\title{
The Validation as Experimental and Numerical of the Values of Thrust Force and Torque in Drilling Process
}

\author{
K. Gök ${ }^{1, *}$, E. Türkes ${ }^{2}$, S. Neseli ${ }^{3}$, H. Saglam ${ }^{4}$ and A. Gök ${ }^{5}$ \\ ${ }^{I}$ Technical Science College, Dumlupinar University, Germiyan Campus, Kütahya, Turkey \\ ${ }^{2}$ Dumlupinar University, Department of Mechanical Engineering, Kutahya, Turkey \\ ${ }^{3}$ Technical Science College, Selcuk University, Konya, Turkey \\ ${ }^{4}$ Vocational School of Kastamonu, Kastamonu University, Kastamonu, Turkey
}

Received 27 December 2012; Accepted 12 December 2013

\begin{abstract}
Drilling is the most common machining process whereby the operation involves making round holes in metallic and nonmetallic materials. Metal drilling operations are quite complex and usually complicated. Nevertheless, knowledge about metal drilling process related to using Finite Element Model in literature is quite limited reported. In this study, a Lagrangian Incremental Finite Element Model selected for the metal drilling process. The drilling force and torque values were obtained using Finite Element Model for AISI 1040 workpiece material. A comparison presented between the drilling force and torque values which are obtained by measured and Finite Element Model, and then a good agreement found between measured and predicted force and torque values.
\end{abstract}

Keywords: Drilling, Force, Torque,, FEM simulation.

\section{Introduction}

Metal drilling operations can be conducted with experimentally, analytically and numerically with Finite Element Method (FEM). Experimental methods have a limited structure in terms of both cost and time. The situations as temperature, cutting force, tool wear, normal and shear stresses, contact pressure and chip formation which is occurs on the cutting tool and between workpiece and tool can be calculated by numerically and graphically FEM. This model provides a great facility, especially for experimental data to determine in advance. Metal cutting analyses are used to investigate the appropriate cutting conditions in machining. There are various studies related to cutting analysis in the literature. There are cases that restrict the use of FEM. Due to the fact that metal cutting operation performs in high temperature and high strain rates, mechanical properties of workpiece material are exactly known. Flow stress curves of workpiece materials must be used especially in the cutting analysis. But today, the flow stress curves of workpiece material are not available. Therefore, tensile tests should be designed and conducted carefully at the different temperatures and strain rates on the workpiece materials.

Many researchers have examined the metal cutting processes using the FEM. Attanasion et al. (1) showed FEM

*E-mail address: kadirgok67@hotmail.com

ISSN: 1791-2377 @ 2013 Kavala Institute of Technology. All rights reserved. analysis as 3D of tool wear, Kose et al. (2) studied effect on to cutting tool stresses of feed rate. In the study carried out by Kim et al. (3), presented with numerical and experimental analyses of the effect of the tool edge on the cutting process. The tool forces and temperature in the steady-state orthogonal cutting process and consideration of the tool edge radius are analyzed by using the FEM. In other study carried out by Duran and Nalbant (4), the bending which has been calculated by Castigliano theorem has been compared with the bending obtained by FEM. Moreover, Jaharah et al. (5) presented the application of FEM in simulating the effect of cutting tool geometries on the effective stress and temperature increased in turning AISI 1045. Dechjarern (6) examined the effect on to cutting performance of rake angle. The purpose of the study carried out by Yanda et al. (7), is to find the optimum combination of tool geometry in machining processes which can minimize the tool wear using FEM. By using a supersonic nozzle of Bareggi et al. (8), it has been possible to obtain benefits in machining comparable with conventional liquid coolants. A supersonic nozzle has been used to generate a high velocity air jet to provide cooling at the tool-chip interface area during metal cutting on a lathe and chip shape, insert and workpiece temperature have been predicted by 3D FEM using the commercial software DEFORM. Numerical simulation was carried out by Ucun and Aslantas ( 9 ) to determine the effect of coating type on the cutting forces, tool stresses, and temperatures. Patrascu and Carutasu (10) presented a FEM model for $3 \mathrm{D}$ simulation of turning process with chip 
breaker tools. Zhou et al. in (11) presented a study of the effect of chamfer angle on tool wear of PCBN cutting tool in the super finishing hard turning. In other study performed by Ozel (12), an updated Lagrangian finite element formulation is used to simulate continuous chip formation process in orthogonal cutting of low carbon free-cutting steel. Some FEM studies which are related to the drilling process can be found in the literature. Yang and Sun (13) have been developed a FEM for drilling process. The temperature of the twist drill bit for the AISI 1040 and Al 7075-T651 materials have been analysed by Ozcelik and Bagci (14). Matsumura et al. (15) presented a numerical simulation for analyse of the cutting temperature in drilling. Mieszczak and Lis (16) presented a 3D FEM for drilling process. Guo and Dornfeld (17) developed a 3D FEM for the simulation of drilling burr formation processes on the $304 \mathrm{~L}$ stainless steel workpiece.

In this study, drilling process was examined by using both FEM and experimental method. Drilling forces and torques on the drill bit during drilling process was obtained by developed FEM. A comparison was made among experimental study and developed FEM.

\section{Experimental and numeric procedures}

\subsection{Metal drilling process}

Drilling tests were carried out on a milling machine (TEZSAN M20MS $9 \mathrm{~kW}$ power and $7500 \mathrm{rpm}$ ) by using HSS/E twist drills with a $3.2 \mathrm{~mm}$ web thickness and $10 \mathrm{~mm}$ in diameter at three different helix angles and point angles. Twist drills used in the tests were manufactured specially in three different helix angles as $20^{\circ}, 25^{\circ}, 30^{\circ}$ (manufactured by Karcan Machinery Industry and Trade). The drilled specimens were AISI 1040 carbon steel that was applied heat treatment before testing. The chemical composition of the test specimens drilled is given in Table 1.

Table 1. Chemical composition of workpiece material AISI 1040

\begin{tabular}{llllll}
\hline $\mathrm{P}$ & $\mathrm{S}$ & $\mathrm{Cr}$ & $\mathrm{Ni}$ & $\mathrm{Mo}$ & $\mathrm{Cu}$ \\
\hline 0,0057 & 0,0207 & 0,156 & 0,109 & 0,0715 & 0,136 \\
\hline
\end{tabular}

Thrust forces and torques were measured by Kistler 9257BA/9272A two-component dynamometer that was connected to $\mathrm{PC}$ via a charge amplifier, condition board and data acquisition card. For data acquisition and graphical showing mathematical processing of force and torque signals were controlled and recorded with the software PCLSADAMViev32. The geometries of the chisel edge and the lips were modified with sharpening to reduce thrust force and torque during drilling. Geometrical parameters of twist drill and drilling parameters used in the tests have been given in Table 2. The drilling depth on the specimens were kept constant as $30 \mathrm{~mm}$ since drilling length should be three times of the twist drill diameter or less than that. Twist drills were sharpened by each drilling test identically such as point angle, clearance angle and concentricity of chisel edge must be within tolerance and coincide right and left.
Table 2. Geometrical data of twist drill and drilling parameters

\begin{tabular}{ll}
\hline \multicolumn{1}{c}{ Parameters } & \multicolumn{1}{c}{ Values } \\
\hline Twist drill material & HSS/E, TS 95/1, include \\
& $10 \% \mathrm{Co}$ \\
Twist drill diameter $(\mathrm{mm})$ & $\varnothing 10$ \\
Helix angle $\left(^{\circ}\right)$ & $20,25,30$ \\
Point angle $\left({ }^{\circ}\right)$ & 118 \\
Feed rate $(\mathrm{mm} / \mathrm{rev})$ & $0.1,0.2,0.3$ \\
Cutting speed $(\mathrm{m} / \mathrm{min})$ & $18,22,28$ \\
\hline
\end{tabular}

\subsection{Drilling test setup}

Before the drilling the test, data acquisition system, the machine tool, the drill bits and the specimens were prepared for testing. The test samples were fixed onto the dynamometer and the thrust force and torque signals obtained from the two-components drilling dynamometer were transferred to data acquisition card in a PC via charge amplifier for evaluation. The experimental set up is shown schematically in Fig. 1. The data were averaged before recording in order to stabilize produced fluctuations in the thrust and torque signals. Before starting the test the machine tool was run $5 \mathrm{~min}$ and also 5 pre-drilling test were conducted for stabilization. A peak thrust force may occur after the initial contact. For the torque, it gradually increases until the full engagement of the drill conical surface and workpiece occurs. Therefore, the force and torque signal were recorded by taking the average of them at the $1 / 4$ and $3 / 4$ stage of each drilling phase. In other words, the signals will be recorded after the overall diameter of drill bit enter the workpiece and stopped before the drill bit not to out of workpiece. A small conical hole was created on the centre of the specimens by drilling to prevent sliding the drill point out, run out the drill during drilling and also to provide the drill point feeding coincide with the drill centre direction. Each test was repeated twice in order to reduce measurement errors to minimum and verify the data recorded.

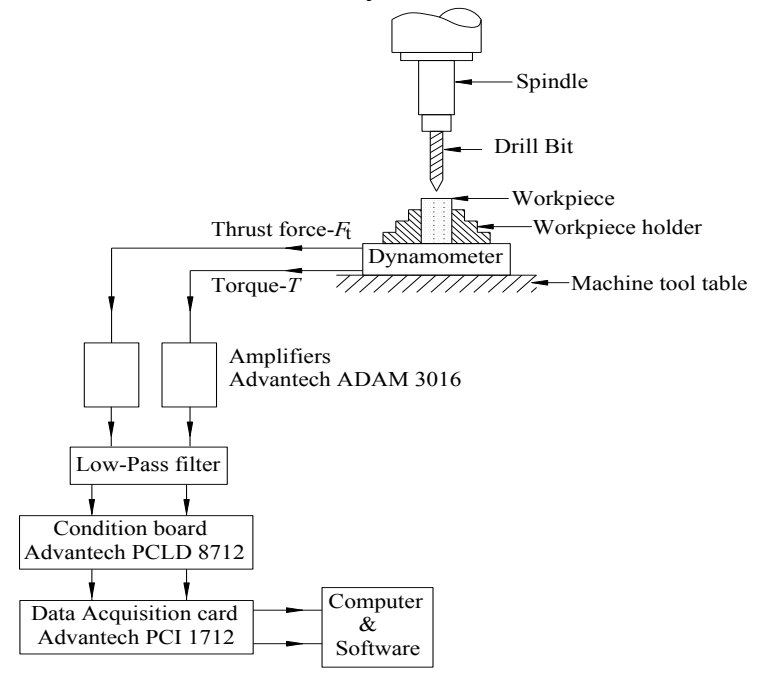

Fig. 1. Schematic layout of experimental set-up for thrust force and torque measurements

\subsection{Finite element method modelling}

At this stage of the study, finite element modelling was used to examine the effect of tool geometry and cutting 
parameters on thrust force and torque in drilling process. A commercial finite element (FE) package "DEFORM 3D" is employed to simulate the drilling process. The geometrical properties of drill bit and workpiece used in the simulation were showed in Fig 2. The drill bits (HSS) were used that have the diameter of $10 \mathrm{~mm}$, point angle of $118^{\circ}$, helical angle of $20^{\circ}, 25^{\circ}$ and $30^{\circ}$, cutting speed of $18 \mathrm{~m} / \mathrm{min}$ and feed rate of $0.1,0.2$ and $0.3 \mathrm{~mm} / \mathrm{rev}$, respectively. The workpiece was simplify shaped as a cylinder which with 50 $\mathrm{mm}$ diameter and $30 \mathrm{~mm}$ height. Because, meshing of the cylindrical models are more easily than others.

Generally, simulations are performed on a spotted or center-drilled workpiece. The spot is roughly at the same angle than that of the chisel edge of the drill. The most holes that are drilled are spotted to allow better circularity of the hole. The spot also improves simulation time significantly because this material doesn't need to be removed by the drill bit. The cutting edge of the drill can start chip formation immediately in the simulation rather than having to wait for the chisel edge to remove material (18).

DEFORM has the ability to use several types of meshes for three dimensional FEM. Historically, the two standard FEM meshes are Eulerian and Lagrangian. There are also combinations such as the Arbitrary Lagrangian Eulerian (ALE) and the Coupled Eulerian Lagrangian (CEL) meshes. Despite the numerous options available, the Lagrangian mesh has been used for all the simulations that have been done for drilling in DEFORM. The iterative solvers that are packaged with DEFORM have been optimized for the Lagrangian mesh and, in turn, simulate much faster than other meshes. Although the Lagrangian mesh is not as comprehensive as the Eulerian mesh, it has much better simulation cycle times as a result. One key advantage of the Lagrangian mesh in simulating drilling processes is the ability to know the entire time history of the key variables at every point during the simulation. That means, if a simulation crashes for any reason, a new simulation can start where the crashed simulation stopped. This is particularly useful because nearly every simulation has some sort of problem during the run. This is possible because the Lagrangian mesh is reformulated at nearly every time step, in order to manage the deformation of the material (18). In this study, a Lagrangian Incremental FEM selected for the metal drilling process.

This three-dimensional FEM of drill bit and workpiece consists of tetrahedral mesh. To improve calculating efficiency, the mesh dimensions around the hole were small, while dimensional in other region were big. The mesh structures of elements of drill bit and workpiece was shown in Fig. 3. While the mesh structure of work piece consists of 52370 elements and 11693 nodes, the mesh structure of drill bit consists of 29931 elements and 7548 nodes. The size ratio of meshes dimensional around the hole was selected as 0.1 , and tip of drill bit was also selected as 0.1 . The side boundary and bottom face of the workpiece was assigned zero displacements in each three directions. The initial temperature of drill tool and workpiece was set the room temperature.

In the earlier analyses of machining, frictional stresses $T_{f}$, on the tool rake face have been considered proportional to the normal stresses $\sigma_{\mathrm{n}}$ with a coefficient of friction $\mu$ based on the Coulomb friction as,
The prevalent conditions at the tool-chip interface constrain the use of the empirical values of the coefficient of friction found from ordinary sliding test conditions. In conventional machining at low cutting speeds, the Coulomb friction can be mostly effective at the tool flank face. However, in high speed machining, a tremendous increase in the chip velocity, the tool-chip friction contact pressure and the temperatures are encountered at the tool rake face.

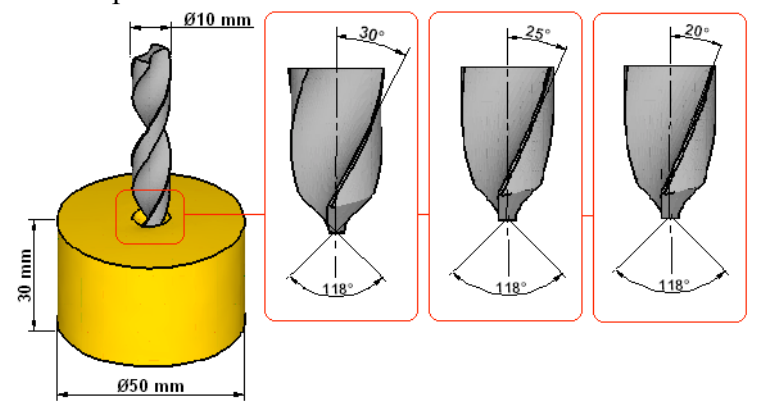

Fig. 2. The geometrical properties drill bit and workpiece used in the simulation

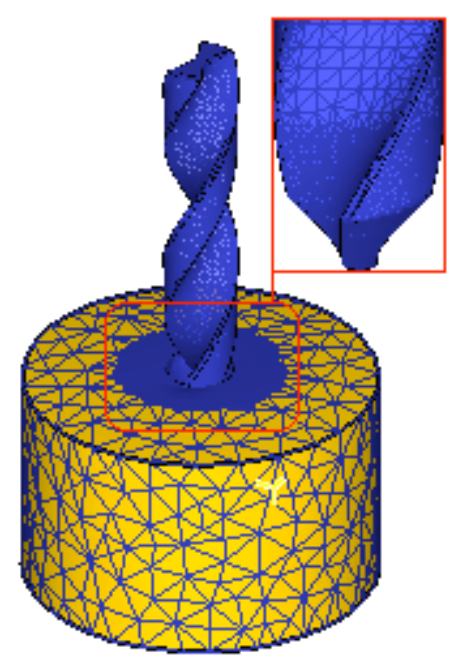

Fig. 3. The mesh structure of twist drill bit and workpiece

As a result, the increasing sliding velocity and frictional stress cause significant wear on the tool rake face. Therefore, the rate of the tool wear depends on heavily the frictional conditions at the tool-chip interface in high speed machining (12). In this study, in order to determine an appropriate coefficient of friction, preliminary simulations were carried out. It was found that using $\mu=0.7$ gave best results in view of cutting forces and torques.

The machining simulation is performed at where $\mathrm{h}=45$ $\mathrm{kW} / \mathrm{m}^{2 \circ} \mathrm{C}$ (19) is assumed the heat transfer coefficient between workpiece material and environment. $\mathrm{T}_{\mathrm{w}}$ and $\mathrm{T}_{0}$ are the temperature of the work material and ambient temperature, respectively (20). ambient temperature assuming the initial temperature is equal to $20^{\circ} \mathrm{C}$. The heat losses to the environment from the free surface of the workpiece material are determined by the heat flux.

$$
Q=h\left(T_{w}-T_{0}\right)
$$


While a twist drill bit (HSS grade) was used as cutting tool in the machining simulation, AISI 1040 carbon steel was used as workpiece material. Mechanical properties of AISI 1040 carbon steel is given in Table 3.

In order to obtain reliable results from the FE solution, it is necessary to input the properties of the workpiece, insert, and coating materials. A material model includes physical and thermal properties of the workpiece and tool. Most importantly, the material model includes the behaviour of the workpiece material under high strain, strain rate and temperature. The Johnson-Cook material model is applicable to high rate deformation of many materials, including AISI 1040. According to the Johnson-Cook model, flow stress is defined below [9]. In this study, the flow stress curve of a material close to AISI 1040 is used.

$$
\bar{\sigma}=\left[A+B(\bar{\varepsilon})^{n}\right]\left[1+C \ln \left(\frac{\dot{\bar{\varepsilon}}}{\dot{\bar{\varepsilon}}_{0}}\right)\right]\left[1-\left(\frac{T-T_{r}}{T_{m}-T_{r}}\right)^{m}\right]
$$

where $\mathrm{A}$ is the yield stress, $\mathrm{B}$ is the strain hardening factor, $\mathrm{n}$ is the strain hardening index, $\mathrm{C}$ is the strain rate sensitivity parameter, $\mathrm{T}$ is the homologous temperature, and $\mathrm{m}$ is the thermal softening coefficient. $\mathrm{Tr}$ is the ambient temperature during the test and Tm represents the melting temperature of the workpiece material. Johnson-Cook model coefficients were calculated using DEFORM-3D software. These parameters were given in Table 4.

Table 3. Material Properties for Simulation Model Cutting Tool Material (HSS) [19]

\begin{tabular}{ll}
\hline Elasticity Modulus (GPa) & 210 \\
Poison Ratio & 0.3 \\
Workpiece Material (AISI 1040) (21) & \\
\hline Elasticity Modulus (GPa) & 210 \\
Poison Ratio & 0.3 \\
Yield Stress (MPa) & 353.4 \\
Ultimate Yield Stress (MPa) & 518.8 \\
Thermal Expansion Coefficient $\left(10^{-6}{ }^{\circ} \mathrm{C}^{-1}\right)$ & 13.6 \\
\hline
\end{tabular}

Table 4. Johnson-Cook model coefficients [19]

\begin{tabular}{llllll}
\hline $\begin{array}{l}\mathrm{A} \\
(\mathrm{MPa})\end{array}$ & $\begin{array}{l}\mathrm{B} \\
(\mathrm{MPa})\end{array}$ & $\mathrm{C}$ & $\mathrm{n}$ & $\mathrm{m}$ & $\begin{array}{l}\mathrm{T} \text { melt } \\
\left({ }^{\circ} \mathrm{C}\right)\end{array}$ \\
353.4 & 102.625 & 0.210019 & 0.298361 & 7.99436 & 1521 \\
\hline
\end{tabular}

\section{Results and Discussion}

The flutes of the twist drill do not cut; they are used to evacuate the chips from the drilled hole. The chisel has a width of $2 \omega$ and an edge angle of $\psi_{\mathrm{c}}$. The cutting lips have an offset from the drill center due to chisel. The lips expand the hole by removing the material with a constant chip thickness (h) as the drill is fed into the material at a feed rate of $\mathrm{c}[\mathrm{mm} / \mathrm{rev}]$. The thrust force that is used to push the drill into the workpiece, and the torque applied to the drill and spindle drive, are required to evaluate the mechanics of the drilling operations. The mechanics of drilling must be analyzed separately for the chisel and cutting lip regions. The chisel edge does not cut but only spreads the material side-ways by an indentation mechanism. Instead of using the laws of cutting, the mechanics of indentation must be used. If the process is simplified as in a hardness test, then the thrust force acting on the chisel edge can be simplified as,

$$
F_{z}=A_{c h} H_{B}
$$

Where $\mathrm{H}_{\mathrm{B}}$ is the Brinell hardness of the workpiece and $\mathrm{A}_{\mathrm{ch}}$ is the instantaneous indentation area of the chisel edge. Approximating the chisel force by the simple indentation method is not reliable for an accurate analysis. The chisel edge geometry and indentation mechanism is rather complex and requires detailed geometric modelling as well as experimental calibration of various empirical factors (22). The geometry of the cutting lip of a drill is quite complex. To use the orthogonal to oblique cutting transformation, it is necessary to identify the helix, normal rake, and oblique angles at cutting points along the lip. Because of the offset caused by the chisel and the varying diameter, the helix, normal rake, and oblique alißgles vary from the chisel-lip to lip- flute intersection (23).

The total thrust force exerted on the drill is found by summing the contributions of the chisel and lip forces. The torque produced by the chisel edge can be neglected. The mechanics of chisel and difficulty in modelling the oblique geometry complicate the mechanics of drilling. Readers are referred to a detailed study presented by Armarego et al. [22]. The grinding of twist drills requires accurate modelling of chisel and lip geometry, as well as rake, helix, and clearance angles along the lip and chisel because strongly influence the cutting mechanics, vibrations, and tool wear.

The FEM has been extensively used to study the drilling process. This method can provide unified approach for drilling and other metal cutting processes. A FE approach was used by Shatla and Altan (24) to determine drilling torque and thrust force. Strenkowski (25) developed an analytical FE technique for predicting the thrust force and torque in drilling with twist drills. The approach was based on representing the cutting forces along the cutting lips as a series of oblique sections.

In this study, FE simulation of drilling process was carried out with the commercial FEA software Deform 3D. The workpiece material was AISI 1040 carbon steel, and the drill bit tool material was HSS. The drill bit tool was considered pufonharder than the workpiece and was taken to be made ${ }^{\natural} \mathrm{C} C$. rigid material. The cutting force and torque values, B2 9 viding with experimental and FEM are given Fig. 4 and Fig 5. In these graphics, a good agreement was found between measured and predicted force and torque values.

In order to verify the prediction of numerical model, the experimental results are compared with the FE results. Figure 6 shows the comparison of thrust force obtained for experimental and FE studies. As seen in Fig. 6, thrust forces decrease as the cutting speed increases for each helix angle. With the increase in cutting speed, temperature on the first deformation zone rises and yield strength of the workpiece decreases. The predicted thrust force is about $0.38 \%$ higher than the measured value for $0.1 \mathrm{~mm} / \mathrm{rev}$. at cutting speed of $18 \mathrm{~m} / \mathrm{min}$.

A general decline in the values of cutting forces can be seen as the cutting speed increases for different helix angles. This fall in the cutting force with increasing cutting speed is more prominent for the $20^{\circ}$ helix angle. One reason for this tendency is that the increasing cutting speed results in an increasing temperature. Therefore, the strength of the material reduces with increasing temperature. This is a typical phenomenon for most metals. Aslantas et al. (26) in a study, they have encountered a similar situation. 
Another comparison between the measured and $\mathrm{FE}$ predicted drilling force and torque value are also shown in Table 5. As can be seen from the table, a good agreement was found between measured and predicted force and torque values. Experiments conducted in this research work involved the study of cutting forces generated during drilling of unidirectional composite. This was done order to study the effect of cutting forces on surface quality and tool wear.

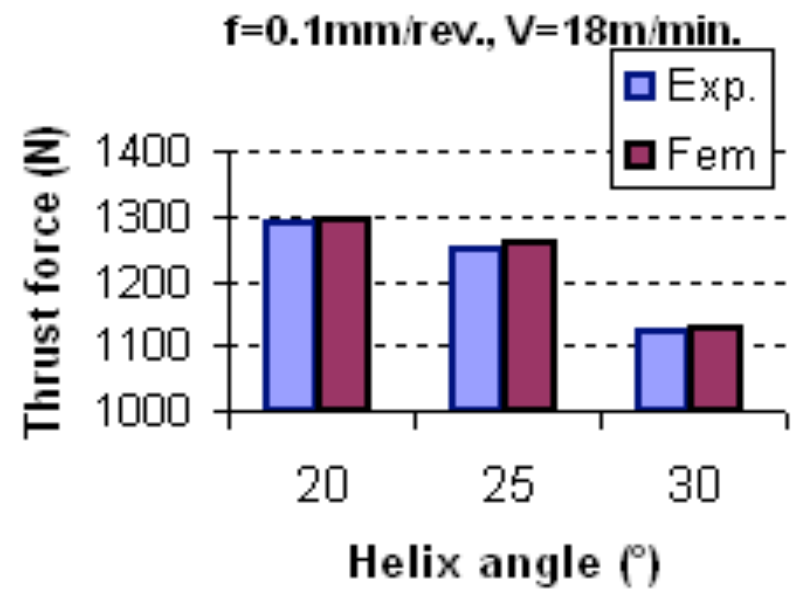

(a)

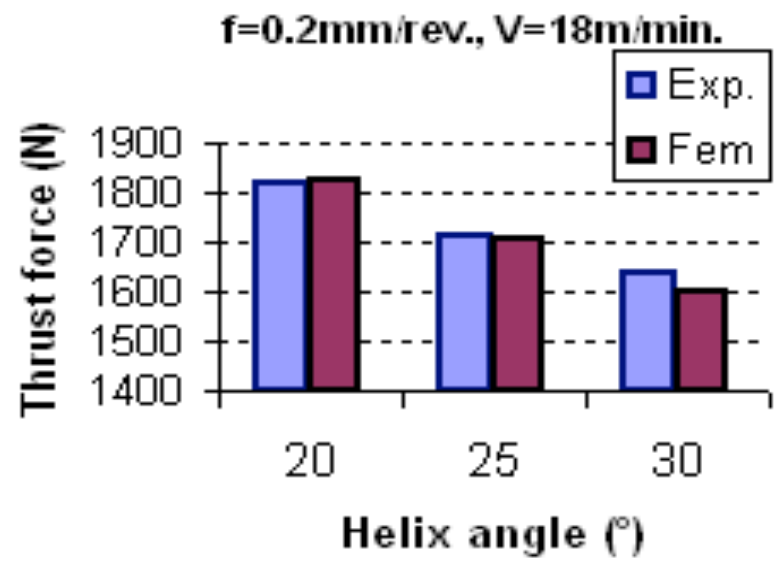

(b)

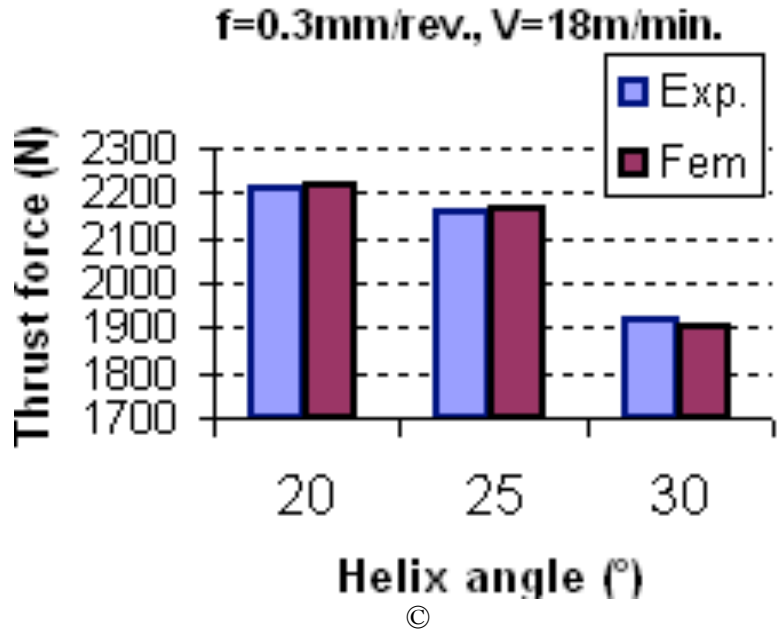

Fig. 4. The comparison measured and predicted thrust force values, $\mathrm{f}=0.1 \mathrm{~mm} / \mathrm{rev}$ a), $\mathrm{f}=0.2 \mathrm{~mm} / \mathrm{rev}$ b), $\mathrm{f}=0.3 \mathrm{~mm} / \mathrm{rev}$ c).

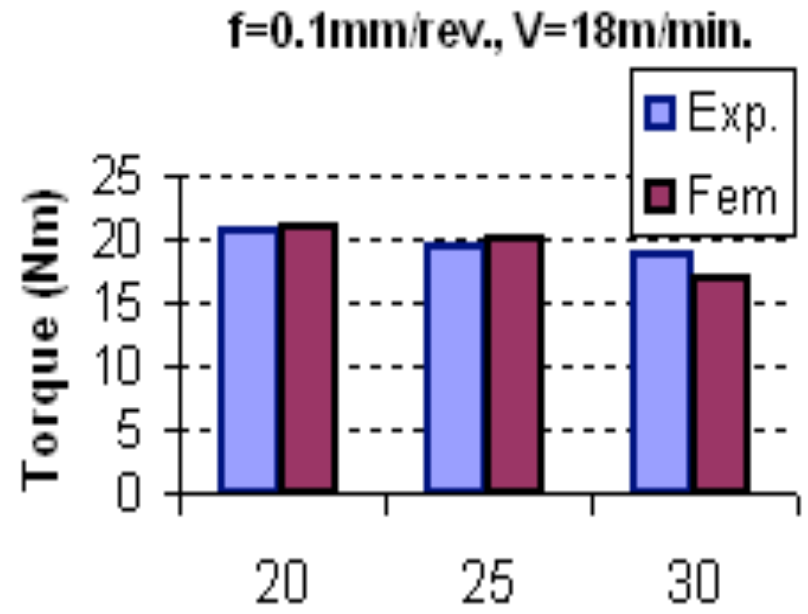

\section{Helix angle $\left({ }^{\circ}\right)$}

(a)

\section{$f=0.2 \mathrm{~mm} / \mathrm{rev} ., \mathrm{V}=18 \mathrm{~m} / \mathrm{min}$.}

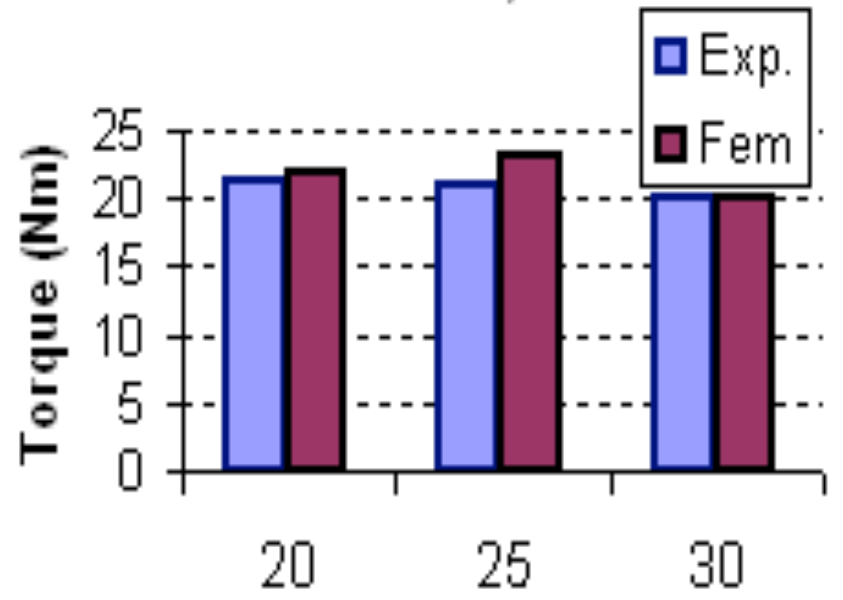

Helix angle $\left({ }^{\circ}\right)$

(b)

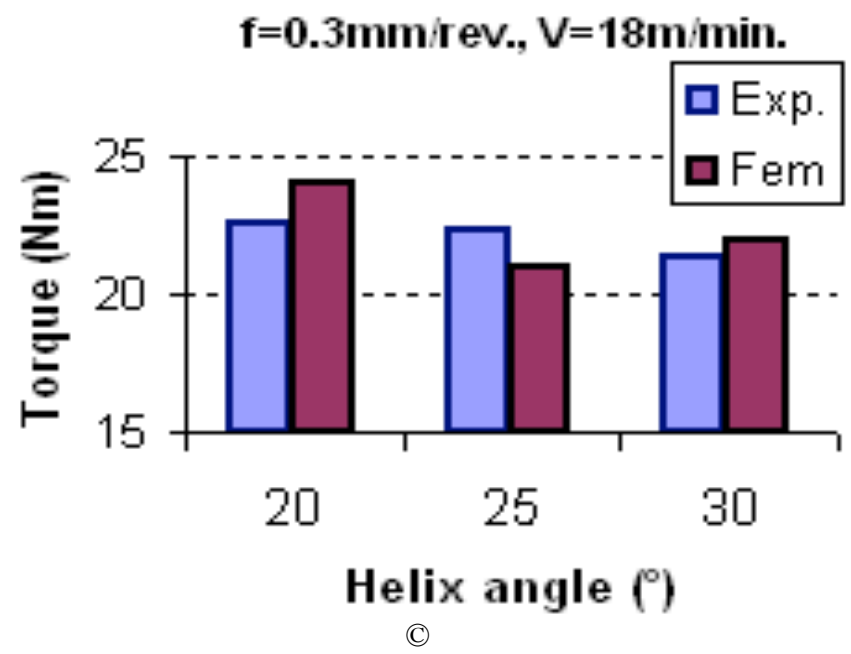

Fig. 5. The comparison measured and predicted torque values, $\mathrm{f}=0.1 \mathrm{~mm} / \mathrm{rev}$ a), $\mathrm{f}=0.2 \mathrm{~mm} / \mathrm{rev}$ ) $), \mathrm{f}=0.3 \mathrm{~mm} / \mathrm{rev}$ c). 


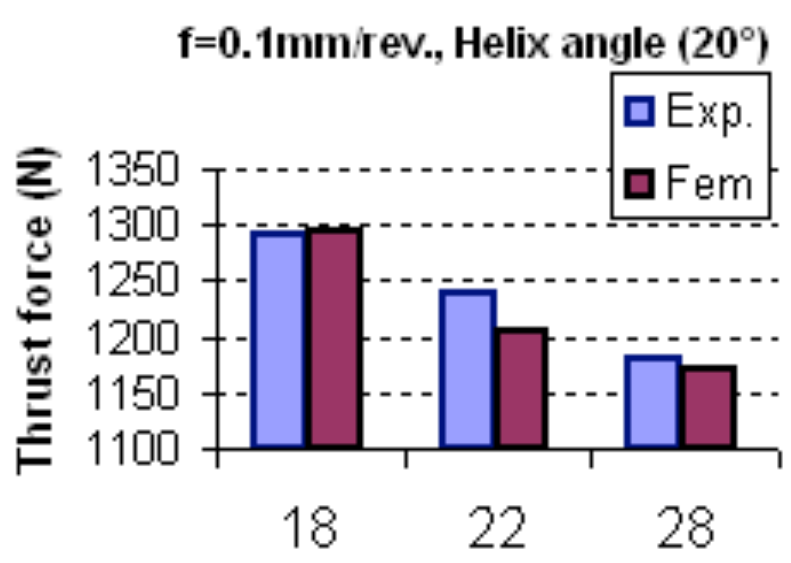

Cutting Speed ( $\mathrm{m} / \mathrm{min}$.)

(a)

$f=0.1 \mathrm{~mm} / \mathrm{rev}$., Helix angle $\left(25^{\circ}\right)$

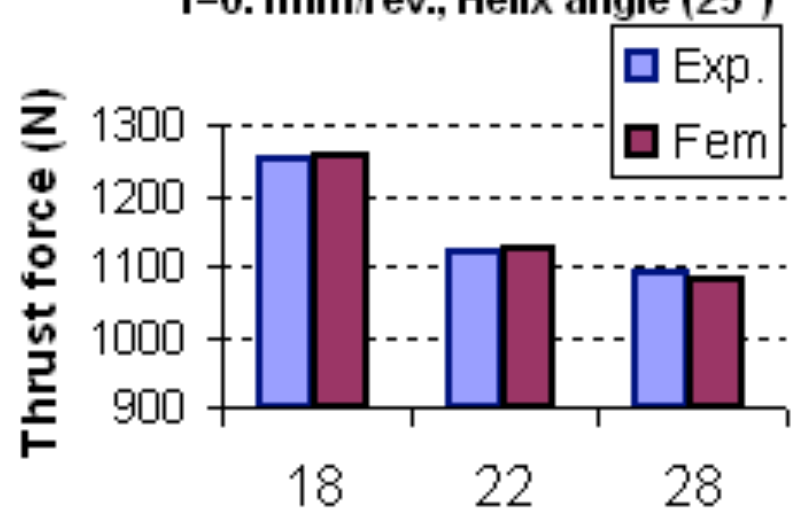

Cutting Speed (m/min.)

(b)

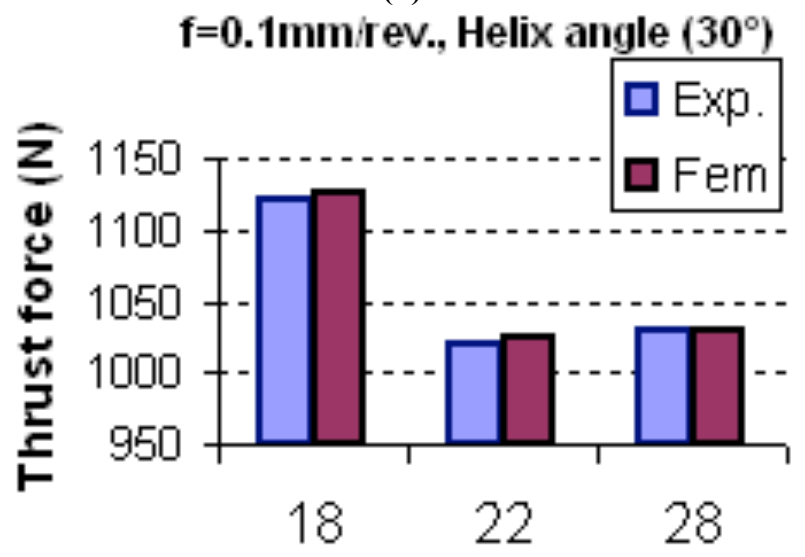

Cutting Speed (m/min.)

(c)

Fig. 6. The variation with cutting speed of measured and predicted thrust force values, $\mathrm{f}=0.1 \mathrm{~mm} / \mathrm{rev}$ and helix angle $\left.\left(20^{\circ}\right) \mathrm{a}\right), \mathrm{f}=0.2 \mathrm{~mm} / \mathrm{rev}$ and helix angle $\left.\left(25^{\circ}\right) \mathrm{b}\right), \mathrm{f}=0.3 \mathrm{~mm} / \mathrm{rev}$ and helix angle $\left.\left(30^{\circ}\right) \mathrm{c}\right)$.

Also, the torque values providing according to time are shown using DEFORM 3D in Fig. 7 in the drill process have cutting speed of $18 \mathrm{~m} / \mathrm{min}$, feed rate of $0.1 \mathrm{~mm} / \mathrm{rev}$ and helix angle of $30^{\circ}$. As shown in Fig. 7, while torque value occurs on the cutting tool rise up to $140 \mathrm{Nm}$, this value is an average of $17 \mathrm{Nm}$ after $0.001 \mathrm{sec}$. of the drilling process. This torque will continue as stable in the later levels of drilling process. Also, the predicted drilling force and torque value providing from this drilling process were compared in Table 5 .

This FEM of drilling involved a great deal of complexity as the drill being a very complex tool and so is the process and the chip geometry. So the pre-processing phase was done considering various parameters from element section, boundary conditions, material properties and the right selection of the pre-processor and solver tool. A FEM has to keep some geometrical properties. To ensure continuity of the approximation, the model has to be topological compatible which implies that elements do not intersect each other but they cover the full object space. Besides, elements border each other at most on vertices or on complete edges or faces. If the shape functions depend only of values on nodes, continuity of the approximation can be obtained. Further the numerical stability of the calculation process can be increased by avoiding obtuse and acute angles. In order to carry out a FEA, the model we are using must be divided into a number of small pieces known as finite elements. Since the model is divided into a number of discrete as a discretization technique. The art of using FEM lies in choosing the correct mesh density required to solve a problem. If the mesh is too coarse, then the element will not allow a correct solution to be obtained. If the mesh is too fine the cost of analysis in computing time can be out of proportion to the results obtained. In order to define a relevant mesh, some idea of the parameter distributions such as stress, temperature, pressure, etc, within the component is required (27).

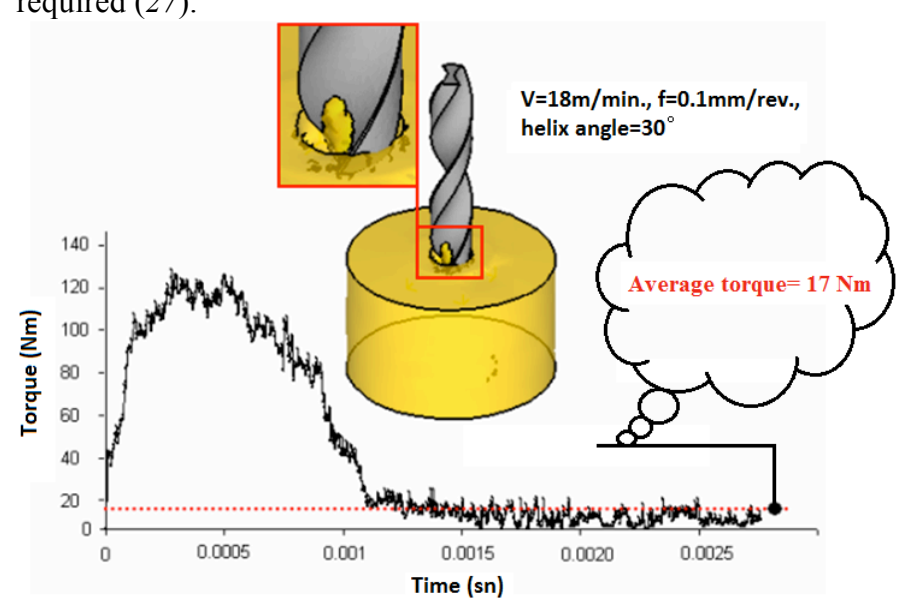

Fig. 7. The predicted torque value in $\mathrm{V}=18 \mathrm{~m} / \mathrm{min}, \mathrm{f}=0.1 \mathrm{~mm} / \mathrm{rev}$, helix angle $=30^{\circ}$

Table 5. Comparison of measured and predicted force and torque value

\begin{tabular}{lllllll}
\hline \multirow{2}{*}{ Helix Angle $\left(^{\circ}\right)$} & & Force (N) & \multicolumn{3}{c}{ Torque (Nm) } \\
& Measured & Predicted & Error (\%) & Measured & Predicted & Error (\%) \\
\hline \multirow{2}{*}{20} & 1290 & 1295 & 0.388 & 20.68 & 21 & 1.55 \\
25 & 1250 & 1257 & 0.56 & 19.45 & 20 & 2.82 \\
30 & 1120 & 1125 & 0.446 & 18.86 & 17 & 9.86 \\
\hline
\end{tabular}

\section{Conclusions}

In this study, drilling process was examined by using both FEM and experimental method. Drill forces and torques occurring on the drill bit during drilling process were obtained by developed FEM. In order to investigate the drilling process, a Lagrangian Incremental FEM of drilling is developed. The drilling process of AISI 1040 carbon steel is predicted based on drilling force and torque values. A good 
agreement was found between measured and predicted force and torque values. While torque value occurring on the cutting tool rises up to $140 \mathrm{Nm}$, this value is an average of $17 \mathrm{Nm}$ after $0.001 \mathrm{sec}$. of the drilling process. This torque will continue as stabile in the later levels of drill process. While experimental torque value is $18.86 \mathrm{Nm}$, predicted torque value is $17 \mathrm{Nm}$. A general decline in the values of cutting forces can be seen as the cutting speed increases for different helix angles. This fall in the cutting force with increasing cutting speed is more prominent for the $20^{\circ}$ helix angle. One reason for this tendency is that the increasing cutting speed results in an increasing temperature. Therefore, the strength of the material reduces with increasing temperature. This is a typical phenomenon for most metals.

\section{References}

1. A. Attanasio, E. Ceretti, S. Rizzuti, D. Umbrello, F. Micari, 3D finite element analysis of tool wear in machining. CIRP Annals Manufacturing Technology 57, 61 (2008).

2. E. Kose, A. Kurt, U. Seker, The effects of the feed rate on the cutting tool stresses in machining of Inconel 718. Journal of Materials Processing Technology 196, 165 (2008).

3. K. Weon Kim, W. Young Lee, H. Chol Sin, A finite-element analysis of machining with the tool edge considered. Journal of Materials Processing Technology 86, 45 (1998).

4. A. Duran, M. Nalbant, Finite element analysis of bending occurring while cutting with high speed steel lathe cutting tools. Mater Design 26, 549 (2005).

5. A. G. Jaharah, S. W. Wahid, C. H. Che Hassan, M. Z. Nuawi, M. N. Ab Rahman, The effect of uncoated carbide tool geometries in turning AISI 1045 using finite element analysis. European Journal of Scientific Research 28, 271 (2009).

6. S. Dechjarern, 3D finite element investigations of the influence of tool rake angle on cutting performance Asian International Journal of Science and Technology in Production and Manufacturing 1, 149 (2008).

7. H. Yanda, A. G. Jaharah, C. H. Che Hassan, Effect of rake and clearance angles on the wear of carbide cutting tool. Engineering eTransaction 4, 7 (2009).

8. A. Bareggi, G. E. O'Donnell, A. Torrance, Modelling thermal effects in machining by finite element methods. Proceedings of the 24th International Manufacturing Conference 1, 263 (2007).

9. İ. Ucun, K. Aslantas, Numerical simulation of orthogonal machining process using multilayer and single-layer coated tools. Int J Adv Manuf Technol 54, 899 (2011/06/01, 2011).

10. G. Patrascu, G. Carutasu, Using virtual manufacturing simulation in 3D cutting forces prediction. Fascicle of Management and Technological Engineering 6, 1423 (2007).

11. J. M. Zhou, H. Walter, M. Andersson, J. E. Stahl, Effect of chamfer angle on wear of PCBN cutting tool. International Journal of Machine Tools and Manufacture 43, 301 (2003).

12. T. Özel, The influence of friction models on finite element simulations of machining. International Journal of Machine Tools and Manufacture 46, 518 (2006).

13. Y. Yang, J. Sun, Finite element modelling and simulating of drilling of titanium alloy. Inf. and Comp. Sci, ICIC '09. Second Int Conf. 4, 178 (2009).
14. B. Ozcelik, E. Bagci, Experimental and numerical studies on the determination of twist drill temperature in dry drilling: A new approach. Mater Design 27, 920 (2006).

15. T. Matsumura, I. Hori, T. Shirakashi, Analysis of cuttinng temperature in drilling process. Int $\mathrm{J}$ Mater Form 3, 499 (2010/04/01, 2010).

16. W. Mieszczak, K. Lis, FEM temperature modelling in drilling process. 14th Int. Res./Expert Conf. "Trends in the Development of Machinery and Associated Technology, 33 (2010).

17. Y. B. Guo, D. A. Dornfeld, Finite element modeling of burr formation process in drilling 304 stainless Steel. Journal of Manufacturing Science and Engineering 122, 612 (2000).

18. J. D. Gardner, D. Dornfeld. (2006).

19. N. Panich, S. Yong, Improved method to determine the hardness and elastic moduli using nano-indentation. KMITL Sci. J. 5, 483 (2005).

20. A. G. Mamalis, M. Horváth, A. S. Branis, D. E. Manolakos, Finite element simulation of chip formation in orthogonal metal cutting. Journal of Materials Processing Technology 110, 19 (2001).

21. h. w. e. c. m. a. c. s. (2012).

22. E. J. A. Armarego, D. Pramanik, A. J. R. Smith, R. C. Whitfield, Forces and power in drilling-computer aided predictions. Journal of Engineering Production 6, 149 (1983).

23. Y. Altintas, Manufacturing Automation: Metal Cutting Mechanics, Machine Tool Vibrations, and Cnc Design. (Cambridge University Press, 2000).

24. M. Shatla, T. Altan, Analytical modeling of drilling and ball end milling. Journal of Materials Processing Technology 98, 125 (2000).

25. J. S. Strenkowski, C. C. Hsieh, A. J. Shih, An analytical finite element technique for predicting thrust force and torque in drilling. International Journal of Machine Tools and Manufacture 44, 1413 (2004).

26. K. Aslantas, I. Ucun, K. Gok, Evaluation of the Performance of CBN Tools When Turning Austempered Ductile Iron Material. Journal of Manufacturing Science and Engineering 130, 054503 (2008).

27. V. Palani, W. S. University, Finite Element Simulation of 3D Drilling in Unidirectional CFRP Composite. (Wichita State University, 2006). 